\title{
PROFESSOR OU TUTOR: UMA LINHA TÊNUE NA DOCÊNCIA EM EAD
}

\author{
(TEACHER OR TUTOR: A TENUOUS LINE IN DISTANCE LEARNING TEACHING)
}

\author{
Michelle Brust Hackmayer \\ UNESA, Brasil
}

Estrella Bohadana

UNESA/UERJ, Brasil

\section{RESUMO}

Este trabalho analisa a natureza docente do trabalho de tutoria na Educação a Distância (EAD), utilizando, como referência, os documentos oficiais do Ministério da Educação e Cultura (MEC) (Brasil, 2007) sobre as funções do tutor e as avaliações que os tutores do Centro de Educação Superior a Distância do Estado do Rio de Janeiro (CEDERJ) fazem de sua prática. Contextualiza a pesquisa, abordando questões teóricas relativas à docência na $\mathrm{EAD}$, a qual envolve vários profissionais em sua atuação, incluindo o tutor. Revela que até o momento inexiste um termo que defina o papel do tutor no trabalho com a EAD, papel este que se torna cada vez maior e mais indefinido. Mostra que, embora tenha, reconhecidamente, uma função importante e determinante nos cursos a distância, o tutor ainda é um profissional que carece de perfil profissiográfico, que lhe confira uma formação definida e um espaço determinado na modalidade. $\mathrm{O}$ artigo revela, ainda, que cresce a necessidade de estudos que indiquem quais as suas principais funções, sua identidade profissional e, sobretudo, a caracterização de sua atuação docente na EAD. Analisa as respostas do questionário aplicado aos 38 tutores do CEDERJ/UERJ, no curso de Licenciatura em Pedagogia e, finalmente, conclui que os tutores são unânimes em considerar sua atuação como docente, embora não sejam reconhecidos nem remunerados como tal pela instituição onde atuam.

Palavras-chave: educação a distância, tutoria, docência.

\section{ABSTRACT}

This research paper analyzes the nature of tutorial work in Distance Learning (DL). It uses as a key reference official documents from the Brazilian Ministry of Education and Culture (MEC) (BRAZIL, 2007), i.e. to describe both the functions of the tutor and the evaluations that tutors from the Center for Distance Higher Education, State of Rio de Janeiro (CEDERJ), implement within their own teaching and evaluation practices. This study contextualizes the 
research by addressing theoretical issues related to teaching in distance education, which involves several professionals, including the tutor. The paper shows that there is a lack of terminology to define the role of the tutor within Distance Education (DEd) - a field which is becoming increasingly complex and more difficult to define. It explains that, although the tutor is recognized as having a significant and specific role in distance learning courses, he or she is still a professional without a professional profile- the latter of which is evidence of a proven educational background and having a certain role within distance learning. This research paper also reveals the growing need to carry out further studies that highlight the teachers' roles, their professional portfolio, and more importantly, their teaching performance and teaching style in DL. It analyzes the answers to the questionnaire that was given to 38 tutors from CEDERJ/UERJ in the undergraduate course in Pedagogy. Finally, it concludes that all participating tutors considered themselves as teachers, even though they were not recognized as such by the institution they worked for.

Keywords: Distance learning, Tutorials,Teaching.

Os recentes e constantes avanços das Tecnologias de Informação e Comunicação (TIC) acabaram por relativizar os conceitos de espaço geográfico e tempo, reduzindo virtualmente as distâncias globais e o tempo gasto para acessar o vasto acervo da produção cultural da humanidade, que ora vem sendo disponibilizado na rede internacional. A emergência dessa "sociedade da informação" configurou uma profunda revolução no campo da produção e disseminação do conhecimento.

Nesse fértil contexto, a modalidade de educação a distância (EAD) foi potencializada, culminando em uma educação acessível e personalizada, não necessariamente melhor, na qual os sujeitos envolvidos têm o relativo privilégio de escolher a melhor forma de ensinar (ou de aprender), além de facilitar a troca de conhecimentos em rede e, com isso, permitir o surgimento de comunidades de aprendizagem.

Outro aspecto a ser considerada na $\mathrm{EAD}$ diz respeito à velocidade com que se dá a oferta de cursos a distância, o que vem fazendo com que os sistemas sejam primeiro criados e utilizados para depois serem quantificados e terem seus resultados avaliados.

A disseminação de cursos superiores de EAD em diferentes polos, principalmente nas cidades interioranas, pretende ser uma iniciativa visando a permitir o acesso à educação de um grande contingente de indivíduos, que não teriam condições de frequentar o curso presencial tradicional pelo fato de morarem longe das universidades ou por indisponibilidade de tempo nos horários tradicionais de aula. É o caso do Centro de Educação Superior a Distância do Estado do Rio de Janeiro (CEDERJ) e, mais recentemente, da Universidade Aberta do Brasil (UAB). 
Além do aumento no número de cursos e alunos, a modalidade EAD mediada pela Internet possibilita a construção de novas figuras profissionais no trabalho docente. Segundo Mill (2012), na docência em EAD algumas relações se criam com novos profissionais participando do processo ensino-aprendizagem, introduzindo, por exemplo, a figura do tutor.

A docência na $\mathrm{EAD}$ não está devidamente profissionalizada, ainda é vista como uma força de trabalho inferior e depreciada em relação à docência presencial (Mill, 2012). O tutor, como parte desse quadro profissional, também sofre grande depreciação, senão a maior delas, no que diz respeito ao seu lugar na $\mathrm{EAD}$, apesar de desempenhar um papel-chave no processo ensino-aprendizagem (Maggio, 2001).

Não existe, até o momento, um termo que defina o papel do tutor no trabalho com a EAD. Nos dicionários e verbetes, os termos tutor e tutoria aparecem relacionados mais diretamente às necessidades e à realidade jurídica que propriamente à atividade educacional.

A esse profissional é dada uma infinidade de denominações, tais como: "tutor virtual, tutor eletrônico, tutor presencial, tutor de sala de aula, tutor local, orientador acadêmico, animador e diversas outras" (Mill, 2008, p. 3). Isso acontece porque os tutores se relacionam mais diretamente com o aluno, despertando nele a motivação e o interesse pelo estudo.

O desenvolvimento de cursos na modalidade a distância permite levantar, refletir e discutir questões relacionadas ao papel, às funções, às tarefas e às inúmeras responsabilidades que o tutor assume quando se dispõe a acompanhar e orientar os alunos no processo ensino-aprendizagem.

As características do tutor de um curso a distância não dizem respeito só a competências administrativas, mas também a aspectos ligados ao relacionamento interpessoal. O tutor deve desenvolver habilidades de relacionamento interpessoal que valorizem um processo de formação flexível e aberta para o diálogo e para a negociação constantes durante a aprendizagem.

Cadatutor, nasuamodalidade, presencialouadistância, assumeresponsabilidades e papéis que vão além de suas funções especificadas no momento de sua contratação e chegada à instituição. Embora tenha, reconhecidamente, uma função importante e determinante nos cursos a distância, o tutor ainda é um profissional que carece de perfil profissiográfico, que lhe confira uma formação definida e um espaço determinado na modalidade. 
Há ainda muito o se que investigar sobre a realidade do tutor na EAD, pois ele é, geralmente, responsável por acompanhar o aluno em todo o seu processo de aprendizagem, desde a orientação de estudos e a explicação dos conteúdos até a avaliação de suas atividades. Entretanto, na maioria das instituições, é dado ao tutor um valor secundário, inferior, entendendo-se que cabe a ele apenas a função de mediar a informação entre o aluno e o material didático, sendo este último autoexplicativo, possibilitando ao aluno aprender sozinho.

A definição que se tem desse profissional, inclusive a difundida nos Referenciais de Qualidade Para Educação Superior a Distância (2007, p. 19), traz a "figura" do tutor como um

[...] dos sujeitos que participa ativamente da prática pedagógica. Suas atividades desenvolvidas a distância e/ou presencialmente devem contribuir para o desenvolvimento dos processos de ensino-aprendizagem e para o acompanhamento e avaliação do projeto pedagógico.

A discussão que se apresenta, nesse caso, refere-se ao significado da função tutorial. Se o tutor é quem acompanha o aluno, trabalha cotidianamente com ele, participa dos processos de avaliação das aprendizagens, entre outras funções, cabe questionar no que essas atribuições são diferentes daquelas dos professores presenciais (Alonso, 2010).

Scheibe (2006) chama a atenção para esse problema, trazendo à cena uma consideração muito relevante quanto à atuação do tutor na EAD. Por mais tênue que possa parecer a fronteira entre o trabalho desse profissional e do professor na $\mathrm{EAD}$, o que se busca realmente é a competência dessa docência para a qualidade na formação dos alunos, para que haja uma efetiva consolidação dessa modalidade de educação.

Considerando a relevância da temática, este artigo tem como objetivo analisar a natureza docente do trabalho de tutoria na $\mathrm{EAD}$, utilizando, como referência, os documentos oficiais do Ministério da Educação e Cultura (MEC) (Brasil, 2007) sobre as funções do tutor e as avaliações que os tutores do CEDERJ fazem de sua prática. Como parte de uma pesquisa mais ampla, que investiga as funções, a identidade e a ação docente do tutor na EAD, este artigo privilegia analisar as respostas dos tutores sobre sua atuação, principalmente se estes se consideram docentes na EAD. 


\section{A DOCÊNCIA NA EDUCAÇÃo A DISTÂNCIA}

No início da utilização da EAD como modalidade de ensino, não havia grande preocupação com a atuação do professor, uma vez que este participava apenas da elaboração dos materiais didáticos. Não havia ainda uma interação do aluno com o professor, o qual não fazia a mediação do processo ensino-aprendizagem. $\mathrm{O}$ rádio e a TV eram as principais tecnologias utilizadas (Rêgo, 2010).

Com os avanços das TIC, acompanhados do uso da Internet e de vários recursos de interatividade, os programas de EAD tiveram de recorrer a outros tipos de materiais para seus cursos, como o "acompanhamento do processo de aprendizagem dos alunos, porque a comunicação passou a apresentar a possibilidade de assumir caráter multidirecional” (Rêgo, 2010, p. 118).

Nesse ponto, os debates e as discussões em torno da EAD fazem surgir a problemática da docência na educação a distância. Para Keegan (apud Belloni, 2001), "em educação a distância quem ensina é uma instituição". Com base nesse pressuposto, Belloni (2001) considera que a definição do papel, das funções e das tarefas docentes em EAD terá de ser necessariamente diferente daquela do ensino convencional. A indefinição conceitual e institucional desses aspectos da docência na EAD reflete-se no papel e nas funções do professor a distância.

As particularidades de formação, saberes e perfil docente passaram então a ser a base das discussões sobre a docência em EAD, pois dizem respeito ao fazer pedagógico docente e à identidade profissional.

Para Belloni (1999), o uso das TIC na EAD torna o ensino mais complexo, dada a segmentação do ato de ensinar em múltiplas tarefas. Seguem-se a lógica e o modelo racionalizado e industrializado do tipo fordista, que se baseiam na divisão do trabalho e são desligados da pessoa do professor, profissional central do ensino convencional.

Como resultado dessa divisão do trabalho, as funções docentes vão separarse e fazer parte de um processo de planejamento e execução dividido no tempo e no espaço, o que torna difícil a identificação de quem é o professor em educação a distância.

No documento do MEC (Brasil, 2007, pp. 20-21), a descrição das categorias e as funções de autor e de coordenador estão expressas no tópico em que são descritas as atribuições dos docentes. As atribuições do tutor são destacadas em outra categoria, 
como se a tutoria não estivesse necessariamente dentro da mesma categoria da docência.

\section{Docentes}

Em primeiro lugar, é enganoso considerar que programas a distância minimizam o trabalho e a mediação do professor. Muito pelo contrário, nos cursos superiores a distância os professorem veem suas funções se expandirem, o que requer que sejam altamente qualificados. Em uma instituição de ensino que promova cursos a distância, os professores devem ser capazes de:

- Estabelecer os fundamentos teóricos do projeto;

- Selecionar e preparar todo o conteúdo curricular articulado a procedimentos e atividades pedagógicas;

- Identificar os objetivos referentes a competências cognitivas, habilidades e atitudes;

- Definir bibliografia, videografia, iconografia, audiografia, tanto básicas quanto complementares;

- Elaborar o material didático para programas a distância;

- Realizar a gestão acadêmica do processo de ensino-aprendizagem, em particular motivar, orientar, acompanhar e avaliar os estudantes;

- Avaliar-se continuamente como profissional participante do coletivo de um projeto de ensino superior a distância.

\section{Tutores}

O corpo de tutores desempenha papel de fundamental importância no processo educacional de cursos superiores a distância e compõe quadro diferenciado no interior das instituições. $\mathrm{O}$ tutor deve ser compreendido como um dos sujeitos que participa ativamente da prática pedagógica. Suas atividades desenvolvidas a distância e ou presencialmente devem contribuir para o desenvolvimento dos processos de ensino, e de aprendizagem e para o acompanhamento e avaliação do projeto pedagógico.

Embora o referencial explicite a relevância do tutor no trabalho da EAD, salta aos olhos a dicotomia existente entre tutor e docente. Nessa perspectiva, docente é o professor que concebe, que cria, que é capaz de gerir o sistema; o tutor é alguém que cumpre o que foi planejado por outro. Essa é uma das questões centrais que 
trataremos a partir daqui, porque para nós é fundamental a compreensão de que o tutor é também um docente, com funções específicas.

O que devemos pensar é que o professor e o tutor são igualmente responsáveis pela qualidade do ensino. Segundo Litwin (2001), a EAD fornece muitas possibilidades de uso de recursos que facilitam a aprendizagem dos alunos, podendo contribuir muito para a dinâmica do curso. Dessa forma, "o papel do tutor é essencial, devemos vê-lo como uma 'ponte móvel' entre o aluno, o curso e o professor" (Litwin, 2001, p. $38)$.

No cenário contemporâneo, segundo Maggio (2001), o docente cria propostas de atividades para reflexão, apoia sua resolução, sugere fontes de informação alternativas, oferece explicações, favorece os processos de compreensão e propõe desafios e novos meios de ensinar e aprender. Isso permite, também, delinear novas definições para o trabalho de tutoria.

A figura do tutor passou a ser reconhecido no Brasil, segundo Machado (2010), como aquele que dá suporte ao aluno dos cursos de EAD. Mas não é só isso, pois do tutor é exigida uma infinidade de habilidades: além de graduados e habilitados para o planejamento e exercício de funções pedagógicas, ter um amplo conhecimento na utilização das TIC e uma profunda compreensão da EAD. Além disso, o tutor ainda deve ter:

[...] disponibilidade de tempo e o necessário ensejo e satisfação pelo trabalho com tecnologias. Comunicar-se adequadamente, em alto nível, sem correr os riscos de transmitir ideias e conceitos utilizando gírias ou jargões da internet é outra característica básica. Ter conhecimento de mundo, informando-se regularmente através da própria web e também da leitura de jornais, revistas, artigos científicos e livros é outro requisito (Machado, 2010, p.30).

Em relação à relevância do papel do tutor na EAD, outros autores também apresentam considerações. Mill (2008, p. 35), de forma sucinta, apresenta funções atribuídas aos tutores. Assim, haveria o "docente-tutor", definido como "elementochave para o desenvolvimento cognitivo do estudante nas atividades individuais e coletivas ao longo da disciplina". Caberia a esse profissional a responsabilidade por "acompanhar, orientar, estimular e provocar o estudante a construir o seu próprio saber, desenvolver processos reflexivos e 'criar' um pronunciamento marcadamente pessoal" (Idem).

Segundo Litwin (2001, p. 49), caberia destacar a importância do tutor para a "compreensão leitora do estudante sobre o material didático escrito, inclusive com 
os guias e manuais de orientações ao desenvolvimento dos contextos do curso e da disciplina". Mill (2008, p. 37) apresenta ainda mais dois autores que fazem referência ao papel do tutor, como:

Flemming et al. (2007) que valoriza a sua capacidade de gerar e/ou manter uma rede de comunicação aberta entre os participantes, promovendo a socialização das ideias e permitindo a construção coletiva de saberes em comum e Gatti (2003) que enfatiza o seu papel na criação de laços sociocognitivos, afetivos e motivacionais, entre o programa e sua proposta e os professores-cursistas. Considera-o um elo privilegiado de comunicação entre os professores-cursistas e o material didático, os projetos de trabalho e os professoresformadores.

Além disso, para Mill (2012), o tutor é tão fundamental para o processo de aprendizagem dos alunos que estes reconhecem nos tutores a própria instituição, vista a estreita relação que se estabelece entre eles. A imagem que o aluno fará da instituição é relativa ao tipo de atendimento recebido do tutor.

Talvez por isso Machado (2004, p. 32) entenda que o tutor exerce suas funções em "contextos que requerem uma análise fluida, rica e flexível de cada situação, a partir da perspectiva dos tempos, das oportunidades e dos riscos que imprimem as condições institucionais da educação a distância”. O desafio maior da tutoria, segundo ele, estaria na possibilidade de diminuir as dificuldades causadas pela distância, tendo com os alunos uma relação eficiente quanto a orientações e sugestões de estudo. Pois, para o autor, a chave do sucesso da EAD depende do tipo de relação que se estabelece entre o tutor e o aluno.

Nesse sentido, Litwin (2001) diz que a diferença fundamental entre o professor da educação presencial e o tutor na EAD é institucional, embora possam ser observadas aí consequências pedagógicas importantes. Os alunos, na maioria dos casos, reconhecem a ação docente do tutor e, em algumas instituições, como é o caso do CEDERJ, os tutores são convidados para serem paraninfos e professores homenageados em formaturas.

O que falta, até o momento, ao tutor é o reconhecimento por parte das instituições do seu papel como docente, mas sabemos que isso envolve não somente questões políticas, mas também financeiras.

Nessa perspectiva, vale reforçar que há diferença entre as funções dos atores envolvidos na docência em EAD, mas que o tutor, como parte desta polidocência, deve ser considerado legitimamente um docente. 


\section{Da pesquisa}

A pesquisa se voltou para uma análise qualitativa das funções dos tutores na educação a distância. A coleta de dados foi realizada por meio da aplicação de questionário a tutores (presenciais e a distância) que atuam no Consórcio CEDERJ, no curso de Licenciatura em Pedagogia da Universidade Estadual do Rio de Janeiro (UERJ).

O questionário foi composto de questões abertas e fechadas, totalizando 20 perguntas. Foi elaborado em meio digital, utilizando as ferramentas do Google, e enviado para os tutores por e-mail. As respostas foram recebidas no período de 01 a 18 de setembro de 2013 .

Com as informações obtidas a partir das perguntas fechadas, foi possível estabelecer um perfil sócio-profissional inicial dos tutores que atuam no curso de Pedagogia do CEDERJ.

Entre os tutores que responderam o questionário, tivemos uma quantidade equilibrada entre tutores presenciais e tutores a distância. Dos 38 tutores que responderam ao questionário, 50\% (19 tutores) eram tutores a distância e 50\% (19 tutores) eram presenciais.

A faixa etária foi bem diversificada, apresentando uma maioria de profissionais com idade acima dos 40 anos (50\%), seguido por um número também grande de tutores com idade entre 36 e 40 anos (21\%), além de $11 \%$ entre 31 e 35 anos. Os mais novos somaram 18\%, sendo $13 \%$ com idade entre 26 a 30 anos e $5 \%$ com idade entre 20 e 25 anos. Esse resultado nos mostra maior maturidade profissional, principalmente se relacionarmos esses dados aos dados de tempo de atuação no ensino presencial, que apresentaram uma maioria de 23 tutores (61\%) com mais de 10 anos de atuação no ensino presencial.

Outro aspecto que observamos nos dados obtidos, ainda quanto à caracterização dos tutores pesquisados, foi sua titulação. A maioria dos tutores (55\%) possui pósgraduação (mestrado), seguido por 34\% de profissionais com especialização e $3 \%$ com doutorado. Somente $8 \%$ tem somente a graduação (exigência mínima para a função). Esse é um quadro bastante favorável quando consideramos que o tutor possui uma qualificação muito semelhante ao exigido de um docente de ensino superior. Cabe atentar também para o fato de que uma das justificativas para a desvalorização desse profissional por parte da instituição e, por conseguinte, para 
um salário menor, é a de que do tutor é exigida uma formação inferior e que sua atuação seria relativa a essa baixa titulação.

\section{Da fala dos tutores}

A partir das perguntas abertas do questionário, elencamos questões referentes à motivação que levou esses profissionais a serem tutores. Muitas razões foram apresentadas em respostas diversificadas:

T3: Sempre me senti atraído a fazer cursos a distância. Morei em uma cidade grande onde perdia cerca de 2 horas preso no engarrafamento e fiz o curso (presencial) com muita dificuldade, pois tinha que trabalhar. Sempre me interessei por tecnologia. Quando descobri os cursos EAD, pra mim foi a junção dos recursos tecnológicos aliado ao tempo que perdia no trânsito. $\mathrm{O}$ aluno EAD passa pelas mesmas dificuldades que enfrentei, e gosto de poder ajudar essas pessoas.

T17: Por acreditar nesta modalidade de ensino e compreender que o Brasil com sua vasta extensão territorial e com suas diferenças regionais, o modelo de educação de que dispúnhamos antes, já não dava conta em função de um conjunto de fatores que dificultava o acesso das pessoas oriundas das regiões norte e nordeste, dentre outros.

T18: Tenho atualmente mais de 40 anos na Educação. Fui docente e coordenadora de curso de graduação em Letras e diretora adjunta de faculdade de educação por cerca de 10 anos, na modalidade presencial. Comecei a ter interesse pela EAD e fiz então um curso de especialização em Educação EAD. Ao me aposentar, surgiu um processo seletivo para o CEDERJ. A partir de 2009.2 comecei a trabalhar com a tutoria a distância. Abriu-me perspectivas conceituais sobre a educação a distância. No início, tinha uma certa reserva em relação à EAD em face da modalidade presencial. Hoje acredito piamente que ambas devem conviver para atendimento de demandas educacionais diversas.

T33: Porque sempre acreditei que o ensino pode percorrer caminhos diversos para alcançar seu objetivo. A ead é um caminho seguro para a educação em todo o mundo. Pude perceber isso quando fiz uma excursão, pedagógica pela instituição educacional em 2000 onde trabalhava, nos países que já utilizavam em grande escala a ead como aliada em formação dos universitários como por exemplo o México, Cuba e Estados Unidos”.

Nessas primeiras falas, podemos perceber que estão sendo valorizadas, como motivação inicial para o trabalho, questões referentes às vantagens do ensino a distância. Os tutores se sentem atraídos por essa "novidade" na forma de fazer educação e por sua vasta possibilidade de melhorar a situação educacional no País, como, por exemplo, a diminuição das distâncias, a facilidade de acesso e a democratização do ensino. Entendemos que esses argumentos fazem parte de um ideal criado pelos próprios tutores, antes mesmo de começarem a atuar na EAD, ideal esse propagado com insistência pelas políticas governamentais de expansão 
do ensino superior. Mas será que, na prática, essas possibilidades estão realmente sendo colocadas em ação? Há que se questionar se a EAD, em nosso país, tem conseguido alcançar esses ideais de expansão e democratização do ensino superior. E, principalmente, se a formação nos cursos de EAD tem sido satisfatória para que se justifique a sua utilização como possibilidade de expansão do ensino superior. De que adiantaria uma enorme expansão sem a devida qualidade?

Outro aspecto abordado pelos tutores diz respeito à flexibilidade do trabalho na EAD. Alguns tutores apontam esse motivo como sendo uma vantagem do trabalho de tutoria, como podemos observar a seguir:

T8: Identificação com a modalidade, flexibilidade permitida e formação continuada foram alguns fatores que influenciaram minha escolha.

T13: Pela facilidade e tempo de trabalhar. E também trabalhar com alunos que as vezes se sentem inseguro no curso que cursa.

Esse é um aspecto que não podemos negar como facilitador para a atuação desses profissionais na $\mathrm{EAD}$, principalmente se considerarmos o acúmulo de turmas em diversas escolas que os professores são obrigados a assumir no ensino presencial para receber um salário melhor. Na prática, as tutorias possibilitariam ao professor assumir mais uma infinidade de turmas em sua carga horária. Mas de que maneira isso poderia de fato melhorar a situação do professor? Como administrar mais turmas além das muitas que ele já possui? $\mathrm{E}$ o atendimento a cada aluno, seria possível que ele acontecesse com qualidade?

Além disso, a tutoria permite que esse professor utilize o fim de semana para trabalhar. Esse é outro argumento apresentado por eles como favorável. Mas não seria um retrocesso nos próprios direitos trabalhistas? Não seria uma luta contrária àquela travada pelos professores, no intuito de conseguir um horário de planejamento dentro da carga horária da escola? De um modo geral, a reivindicação dos professores é justamente a diminuição da carga de trabalho durante seu horário de folga. Parece-nos uma grande incoerência.

O que percebemos também é que, aos poucos, esses mesmos tutores começam a descobrir que essa flexibilização tem outro aspecto, por vezes negativo, de exigir um tempo enorme de planejamento, elaboração e execução da tutoria. Além, é claro, de um plantão quase permanente na plataforma para dar conta de muitos alunos (a maioria tem cerca de 300 alunos), da correção de todas as provas presenciais e de todas as outras múltiplas funções que lhes são impostas pela instituição. 
Os tutores descobrem, com o tempo, que já não basta o número de horas estabelecido pela instituição para plantões de atendimento ao aluno. Na tutoria a distância, as respostas aos alunos na plataforma devem ocorrer num prazo máximo de 48 horas. Sendo assim, a sua dedicação acaba sendo infinitamente maior do que o previsto para dar conta de todas essas atividades.

Mas, além disso, percebemos motivos mais relacionados à atuação pedagógica em si, e estes, sem dúvida, são os mais enriquecedores na experiência com a tutoria em $\mathrm{EAD}$, inclusive fazendo com que muitos desses profissionais se mantenham nessa função, apesar das dificuldades. Abaixo apresentamos algumas dessas falas:

T16: A pesquisa de mestrado me levou a tutoria, para pesquisar sobre o cotidiano, devemos estar imersos nele. Para dissertar sobre a EAD, foi necessário estar inserida neste universo. Hoje não me vejo fora da EAD.

T15: Inicialmente pela oportunidade, porém a possibilidade de interação tutor-aluno é interessante.

Como vimos, são muitos os motivos que levaram esses tutores a ingressar no trabalho com a EAD, mas, para a maioria, sua maior motivação foi a possibilidade de trabalhar com o ensino superior. Isso nos levou a pensar na questão da docência exercida pelos tutores na sua atuação na EAD, e tivemos interesse de indagar-lhes se consideravam a tutoria uma ação docente. O resultado foi unânime. Todos os tutores participantes consideram sua ação como docência. Eis alguns dos argumentos:

T1: Sim, a prática docente é uma atividade indissociável da atividade de tutoria.

T2: Claro. Sou professora. Tutoria é docência.

T9: Claro! A riqueza de troca nos ambientes virtuais é imensa e não necessariamente se aprende porque estamos juntos numa mesma sala, se aprende porque temos experiências diversas e interesse em compartilhá-las com outras pessoas.

T10: Acredito porque na tutoria vivemos momentos de aprendizagem, há envolvimento emocional, troca de conhecimentos, é necessário didática para alcançar a aprendizagem de todos. É um momento rico, onde ao mesmo tempo que ensino aprendo muito.

T17: Certamente. Na medida em nos preocupamos com o aprendizado dos alunos e por esta razão, buscamos outras formas de ajudá-los neste processo de Ensino/aprendizagem, seja por meio de chat ou até mesmo, fóruns realizados especificamente para oportunizar a produção do conhecimento entre seus pares e, desta forma, fazer com que os alunos que até então, não haviam compreendido algum tópico, tivessem a oportunidade de discutir e refletir a partir das considerações dos seus colegas mediada pelo tutor, neste caso. 
T28: Sim considero, embora não seja tratado como tal, pois orientamos os alunos, ajudamos na confecção e correção das provas, ajudamos na atualização do material didático, entre outras atividades que são exercidas por um professor.

T30: Sim. Enfim, auxiliamos na orientação dos estudos; nas dúvidas frequentemente apresentadas pelos alunos nos conteúdos abordados; orientamos pesquisas; somos parte de uma relação: aluno-disciplina. Tudo que um professor em aula presencial faz, com a diferença que fazemos por computador (muito mais que telefone), quase "on line" e com muito mais critério na forma de explicar e se fazer entender de forma escrita. Para mim, um exercício e um aprendizado por vez.

Podemos perceber nessas falas a confirmação do entendimento do tutor do que representa uma ação docente no ensino presencial, fazendo a transferência desse trabalho para a EAD. Eles identificam essas atividades de docência em seu trabalho de tutoria nos aspectos que se referem ao atendimento ao aluno como principal objetivo da educação. Confirmam a visão de Bruno e Lengruber (2009), para quem o tutor é um mediador pedagógico do processo de ensino e aprendizagem, sendo ele o profissional que assume a docência na EAD.

Outros aspectos vão além dos apresentados acima, como a questão da formação/ titulação desse profissional para a atuação na tutoria, como podemos observar a seguir:

T7: Sem sombra de dúvida é uma ação docente. O tutor é um professor. É especialista no assunto, tem titulação para assumir uma turma de um curso de nível superior, precisa conhecer muito bem o conteúdo o qual faz referência diante das dúvidas dos alunos, precisa ter didática para explicar e dar exemplos, precisa ser parceiro e companheiro do aluno.

T18: Sim. Ao tutor cabe a interação com os estudantes e a explicação prática dos assuntos apontados pelo coordenador da disciplina no Cronograma e trabalhados nas aulas do Material Didático. Inclusive, exige-se do tutor formação acadêmica na área e experiência profissional.

Esse é um aspecto que deve ser percebido com especial atenção, pois, conforme os tutores pesquisados, essa função dá indícios de uma atuação no ensino superior, como é considerado por eles o campo de atuação como tutor. Além disso, demonstram em algumas falas uma percepção inicial de que a docência na EAD é uma docência compartilhada, conforme abordamos no quadro teórico dessa pesquisa:

T6: Sim, mesmo não tendo participação ativa no planejamento da disciplina, essa função está na linha de frente do contato com o ensino, que o aluno da EaD tem. 
T26: Acredito que na EaD todos os agentes realizam uma ação docente. Na verdade toda a equipe se envolve de alguma forma para favorecer a aprendizagem dos alunos.

Esses argumentos são esclarecedores para compreendermos que, além da visão dos autores sobre a docência exercida pelos tutores, como podemos perceber em Bruno e Lengruber (2009), que utilizam o termo professor-tutor para designar o tutor por entenderem que o tutor é também um docente e não somente um animador, monitor ou repassador de pacotes instrucionais, os próprios tutores se consideram como tal. E, principalmente, o que observamos é que não há dúvidas quanto a essa atuação docente com os alunos do ensino superior, motivação inicial de seu ingresso na tutoria. Todos os tutores responderam a essa questão com total segurança e convicção sobre sua ação docente.

A partir da constatação dos tutores, a ação da tutoria vem acompanhada de uma valorização muito pequena de sua atuação pela instituição pesquisada. Ademais, apesar de os tutores se considerarem docentes, a instituição não os reconhece como tal. Essas visões foram obtidas a partir da seguinte pergunta: Acredita haver um reconhecimento por parte da instituição ao seu trabalho como tutor? Por quê? Estas foram algumas das respostas:

T2: O reconhecimento é insuficiente. Toda hora escuto que tutor não é professor. Tutor é tipo professor, só que ganha menos?

T11: Nenhum. Não há regulamentação da área.

T14: Em termos gerais não. Esse reconhecimento fica mais por conta do coordenador que souber aproveitar e dialogar com os conhecimentos e habilidades do tutor. A Instituição vem tratando o tutor como mão de obra barata, não valorizando de uma maneira devida o seu trabalho e a sua formação.

T16: Se a Universidade e o CEDERJ reconhecem a atuação dos tutores, estão esquecendo-se de dizer. Quanto a minha equipe, somos motivados o temo todo e o maior reconhecimento é o retorno dado pelos estudantes que consideram nosso desenho didático diferente, inovador e interativo.

T17: Neste quesito, ainda temos muito a avançar. Haja vista a nomenclatura designada "tutor", onde na verdade, somos professores.

Além das colocações acima, no que tange à valorização do tutor pela instituição, percebemos claramente na fala dos tutores uma associação da falta de valorização com a forma de contrato de trabalho e a remuneração insatisfatória. As falas a seguir mostram um pouco esse quadro de insatisfação: 
T3: Não. O fato de haver bolsa de estudos não caracteriza reconhecimento. Deveria haver concurso público nos moldes semelhantes à instituição que oferece o curso. Um professor presencial da instituição que trabalho chega a receber 400\% (com o mesmo nível de escolaridade que eu) a mais que um tutor, e ainda não temos estabilidade nem vínculo empregatício. Mas isso não é um problema da instituição CEDERJ, é um problema de todos os cursos da UAB.

T4: Não. Não há reconhecimento do trabalho e algumas vezes acontece mesmo o atraso de pagamento sem qualquer justificativa.

T7: Não acredito, sinceramente. Como eu já argumentei, não há vínculo do tutor com nenhuma instituição a qual ele presta serviço. E é exatamente isso: prestação de serviço [que é contra a lei, diga-se de passagem, afinal, atividade fim não pode ser terceirizada] Os tutores são prestadores terceirizados. Não recebem abono, nem aumento, nem parabéns, nem qualquer tipo de gratificação. No termo de outorga há uma cláusula que diz que o contrato pode ser cancelado a qualquer momento sem que o contratado possa discordar. Então, acho que não há reconhecimento...

T9: Não. Principalmente em função da baixa remuneração da atividade. É uma atividade que envolve a formação de professores, mas ao mesmo tempo nós, formadores, não recebemos uma bolsa condizente com uma função tão importante que é a tutoria...

T38: Não. Essa desvalorização é notória. Vemos a remuneração, a relação da coordenação com tutores, a universidade tratando a EAD como algo menor. Não evidenciam a importância da mesma e número de pessoas que contempla.

O que percebemos na fala dos tutores é que, para eles, a maior evidência da falta de reconhecimento do seu trabalho por parte da instituição diz respeito ao aspecto financeiro e trabalhista. As queixas se repetem quanto ao pagamento por bolsas de estudo, configurando a ausência de vínculo empregatício, a falta de estabilidade no cargo e, principalmente, a um salário que não faz jus às exigências do cargo. Mattar (2012) reforça que há uma desvalorização desse material humano quando observa que, antes de mais nada, essa é uma questão trabalhista, de exploração e ideológica.

Essa desvalorização por parte da instituição é percebida pela maioria dos tutores pesquisados. E deparamos, ainda, com um quadro já discutido pela literatura no que concerne ao trabalho importante, porém desvalorizado, do tutor, como nos mostram Bruno e Lengruber (2009):

(...) implicados na qualidade dos cursos e no comprometimento com a aprendizagem dos alunos, não se justifica remuneração especialmente desvalorizada do professor tutor, como temos acompanhado nos cursos online, que precariza a própria docência. Tampouco a denominação de tutoria, que descaracteriza a função docente para profissionais que assumem a mediação pedagógica (p.7). 
O que percebemos, afinal, é que a instituição pouco valoriza a atividade de tutoria e, consequentemente, descuida da qualidade da formação dos seus alunos, visto que o tutor, como grande responsável pela docência na EAD, será também o grande responsável pela formação desses alunos.

\section{CONSIDERAÇÕES FINAIS}

A partir da leitura dos dados e da análise das informações, obtivemos um retrato de como esses tutores percebem sua atuação e como realizam as principais ações práticas relacionadas à sua função. Percebemos que, na maioria, os tutores ingressaram na tutoria do CEDERJ motivados pela possibilidade de atuar na docência do Ensino Superior. Para tal, apresentaram uma boa experiência como professores de cursos presenciais, uma formação condizente com a função docente em questão, mas, mesmo assim, não são considerados docentes na instituição em que atuam.

Confirmamos a amplitude da responsabilidade do tutor como agente que participa efetivamente do processo de ensino-aprendizagem dos alunos, bem como de sua formação intelectual; que os tutores assumem a maior parte da responsabilidade do aprendizado desses alunos, mas que toda essa responsabilidade não recebe o devido valor por parte da instituição, visto que, dentre suas maiores queixas, está a falta de uma vinculação de trabalho e de um salário condizente com sua função.

Em conseqüência dessa desvalorização, surge outro problema, freqüente na instituições de $\mathrm{EAD}$, que é a rotatividade de profissionais. Isso acontece porque os melhores profissionais acabam por ficar desestimulados e desistem da função, sendo substituídos, muitas vezes durante o andamento dos cursos, prejudicando fortemente a formação dos alunos.

A realização desta pesquisa serviu para percebermos que a identidade do tutor ainda está em construção e que, teoricamente, nem mesmo sua função está definida. No entanto, a prática tutorial traz à tona aspectos que podem complementar a conceituação e o entendimento dessa função profissional. A reflexão e a discussão sobre a identidade do tutor, suas funções a sua ação docente são essenciais para uma melhor compreensão e valorização desse profissional na EAD. 


\section{REFERÊNCIAS BIBLIOGRÁFICAS}

Alonso, K. M. (2010). A expansão do ensino superior no Brasil e a EAD: dinâmicas e lugares. Educ. Soc., 31 (113), Campinas, (1319-1335), out.-dez. 1335. [em línea] Disponível em: http://www.cedes. unicamp.br (consulta 2013, 10 de junio).

Alves-Mazzotti, A. J.; Gewandsznajder, F. (2001). O método nas ciências naturais $e$ sociais: pesquisa quantitativa $e$ qualitativa. São Paulo: Pioneira.

Belloni, M. L. (2006). Educação a distância. 4 ed. Campinas: Autores Associados.

Brasil. (2007). Ministério da Educação. Secretaria de Educação a Distância. Referenciais de qualidade para educação superior a distância. Brasília.

Bruno, A. R.; Lengruber, M. S. (2009). Dialética professor-tutor na educação online: o curso de Pedagogia-UAB-UFJF em perspectiva. In: III Encontro Nacional sobre Hipertexto, Belo Horizonte, 2931 out. [em línea] Disponível em; www. ufpe.br/nehte/hipertexto2009/anais/a/ a-dialetica-professor-tutor.pdf (consulta 2013, 6 de julio).

Flemming, D. M.; Luz, E. F.; Luz, R. A. (2001). Monitorias e tutorias: um trabalho cooperativo na educação a distância. (10) [em línea] Disponível em: www. abed.org.br/publique/cgi/cgilua.exe/ sys $/$ start.htm? UserActiveTemplate $=4$ abed\&ind $=142 \& \operatorname{sid}=114 \% 20 \quad$ (consulta 2013, 30 de mayo).

Litwin, E. (2001). Educação a distância: temas para debate de uma nova agenda educativa. Porto Alegre: Artmed.
Machado, L. D; Machado, E. C. (2004.) O papel da tutoria em ambientes de EAD. In: Anais do XI Congresso Internacional de Educação a Distância, Salvador, BA.

Maggio, M. (2001). O tutor na educação a distância. Em: Litwin, E. (Org.) Educação a distância: temas para debate de uma nova agenda educativa. Porto Alegre: Artmed, (93-110).

Mill, D. (2012). Docência virtual: uma visão crítica. Campinas: Papirus.

Mill, D. (2008). Educação a distância: desafios contemporâneos. São Carlos: EdUFSCar.

Rêgo, M. C. L. C. (2010). Tutoria e formação humana no ensino superior a distância. 157 f. Tese (Doutorado em Educação), UERJ, Rio de Janeiro.

Rizzini, I. (1999). Pesquisando: guia de metodologias de pesquisa para programas sociais. Rio de Janeiro: USU.

Scheibe, L. (2006). Formação de professores: dilemas da formação inicial a distância. Educere et Educare, l (2), Cascavel, (199212).

Tractemberg, L.; Tractemberg, R. (2007). Seis competências essenciais da docência on-line independente. In: Congresso Internacional da $A B E D, 13$, Curitiba. [em línea] Disponível em: http:// www.abed.org.br/congress02007/ tc/552007113218PM.pdf (consulta 2013, 7 de julio).

\section{PERFIL ACADÊMICO E PROFISSIONAL DOS AUTORES}

Michelle Brust Hackmayer. Mestranda do Programa de Pós-graduação em Educação da Universidade Estácio de Sá - RJ, na linha de pesquisa de Tecnologia da Informação e comunicação em processos educacionais (TICPE), Tutora do CEDERJ/ UERJ, Técnica em Assuntos Educacionais da UFRJ. Seu foco de pesquisa é a tutoria na Educação a Distância.

E-mail: michellebrust@yahoo.com.br 
Estrella D'Alva Benaion Bohadana. Professora Adjunta do Programa de Pós-graduação em Educação da UNESA, Linha TICPE. Professora Adjunta da UERJ. Doutorado em Comunicação na UFRJ, na linha de pesquisa História dos Sistemas de Pensamento e Mestrado em Engenharia de Produção na UFRJ/COPPE. Autora de livros e artigos. Seu foco de pesquisa atual é mediação docente no ensino superior em AVA e ambientes não formais de aprendizagem como as redes sociais.

E-mail: ebohadana@gmail.com

\title{
ENDEREÇO POSTAL
}

\author{
Michelle Brust Hackmayer \\ Rua Oito de Dezembro 306, apto 506 bloco 2 \\ Maracanã - Rio de Janeiro - Brasil \\ CEP: 20550-200 \\ Estrella D'Alva Benaion Bohadana \\ Rua Cândido Mendes, 383, apto 202 \\ Gloria - Rio de Janeiro - Brasil \\ CEP: 20241-220
}

Fecha de recepción del artículo: 06/12/13

Fecha de aceptación del artículo: 02/05/14

\section{Como citar este artículo:}

Brust Hackmayer, M.; Bohadana, E. (2014). Professor ou tutor: uma linha tênue na docência em EAD. RIED. Revista Iberoamericana de Educación a Distancia, volumen $17, \mathrm{n}^{0}$ 2, pp. 223-240. 